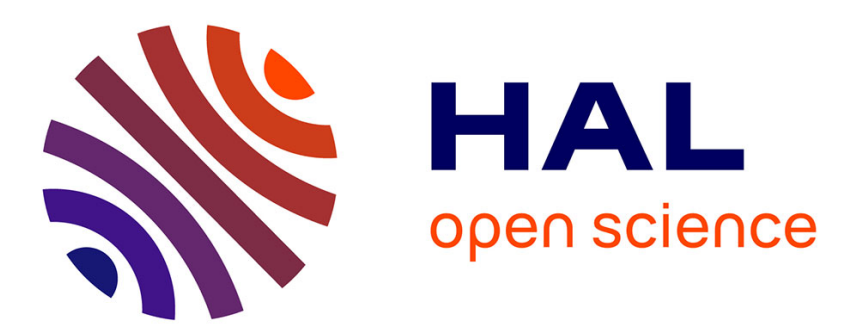

\title{
Facile Fabrication of Polymer Electrolytes via Lithium Salt-Accelerated Thiol-Michael Addition for Lithium-Ion Batteries
}

Ke Jiang, Jirong Wang, Cai Zuo, Shaoqiao Li, Sibo Li, Dan He, Haiyan Peng, Xiaolin Xie, Rinaldo Poli, Zhigang Xue

\section{- To cite this version:}

Ke Jiang, Jirong Wang, Cai Zuo, Shaoqiao Li, Sibo Li, et al.. Facile Fabrication of Polymer Electrolytes via Lithium Salt-Accelerated Thiol-Michael Addition for Lithium-Ion Batteries. Macromolecules, 2020, 53 (17), pp.7450-7459. 10.1021/acs.macromol.0c01302 . hal-02948181

\section{HAL Id: hal-02948181 \\ https://hal.science/hal-02948181}

Submitted on 1 Mar 2021

HAL is a multi-disciplinary open access archive for the deposit and dissemination of scientific research documents, whether they are published or not. The documents may come from teaching and research institutions in France or abroad, or from public or private research centers.
L'archive ouverte pluridisciplinaire HAL, est destinée au dépôt et à la diffusion de documents scientifiques de niveau recherche, publiés ou non, émanant des établissements d'enseignement et de recherche français ou étrangers, des laboratoires publics ou privés. 


\section{Facile Fabrication of Polymer Electrolytes via Lithium Salt-Accelerated Thiol-Michael Addition for Lithium-Ion Batteries}

Ke Jiang, ${ }^{\dagger}$ Jirong Wang, ${ }^{\dagger}$ Cai Zuo,${ }^{\dagger}$ Shaoqiao $\mathrm{Li},{ }^{\dagger}$ Sibo $\mathrm{Li}^{\dagger}{ }^{\dagger}$ Dan He,${ }^{\dagger}$ Haiyan Peng, ${ }^{\dagger}$ Xiaolin Xie, ${ }^{\dagger}$ Rinaldo Poli, ${ }^{*}, \dot{*}$ and Zhigang Xue ${ }^{*, \dagger}$

${ }^{\dagger}$ Key Laboratory for Material Chemistry of Energy Conversion and Storage, Ministry of Education, School of Chemistry and Chemical Engineering, Huazhong University of Science and Technology, Wuhan 430074, P. R. China. ${ }^{\star}$ CNRS, LCC (Laboratoire de Chimie de Coordination), Université de Toulouse, UPS, INPT, 205 Route de Narbonne, BP 44099, F-31077 Cedex 4, Toulouse, France.

For Table of Contents Use Only

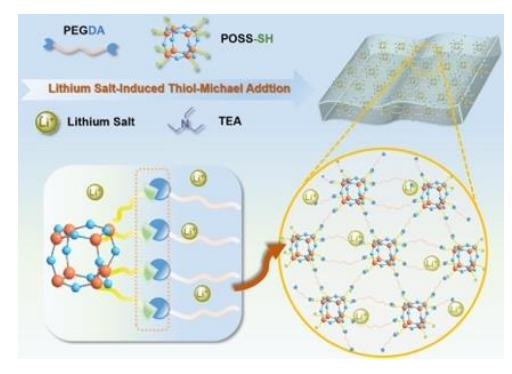

ABSTRACT: Polymer electrolyte (PE) which possesses improved thermal and mechanical stability is believed by far one of the most promising electrolytes for meeting the safety and performance needs of advanced electrochemical devices. Here, 
high-performance PEs are fabricated via facile thiol-Michael addition catalyzed by triethylamine in the presence of lithium salts. The lithium salt functions as both ion source and co-catalyst, significantly accelerating the thiol-Michael addition reaction. The PEs exhibits a superior thermal decomposition temperature up to $300{ }^{\circ} \mathrm{C}$. Additionally, PEs from the thiol-decorated polyhedral oligomeric silsesquioxane display reversible electrochemical response and stable cycling performance. Our finding based on a self-catalyzed strategy provides a promising direction for rapidly fabricating PEs that meet electrochemical requirements for practical solid polymer batteries.

\section{INTRODUCTION}

The increasing demand for electric vehicles and efficient energy storage devices promotes the development of rechargeable batteries with high energy density and long cycle life. ${ }^{1-6}$ However, lithium-ion batteries (LIBs) with liquid organic electrolytes have brought security and reliability concerns owing to inherent limitations such as high volatility, leaks, and explosions. ${ }^{7,8}$ It is thus expected that replacing conventional liquid organic electrolytes with polymer electrolytes (PEs) can improve the Li-based battery safety, performance, and machinability. ${ }^{9-12}$ The poly(ethylene oxide) (PEO) has been most widely studied for PE systems because of its high dielectric constant and ability to form complex with lithium salts. ${ }^{13,14}$ Nevertheless, lithium-salt doped PEO exhibits low ionic conductivity at room temperature originating from its semi-crystalline nature, which hampers the transport of lithium ions through the polymer chain segments. ${ }^{15}$ 
Building a cross-linked framework ${ }^{16-21}$ or loading inorganic components into the polymer matrices ${ }^{22-28}$ can efficiently improve ionic conductivity by inhibiting the crystallization and simultaneously enhance the mechanical properties of the PEs.

The thiol-ene reaction can generally proceed via either radical-mediated antiMarkovnikov addition or base- or nucleophile-catalyzed thiol-Michael addition. ${ }^{29-31}$ Owing to the rapid reaction kinetics, high efficiency, chemo-selectivity, and benign reaction conditions, the thiol-ene reaction has become a particularly useful tool in polymer chemistry and materials science, ${ }^{32-36}$ including polymer network construction, surface functionalization and dendrimer synthesis. For instance, Saito et al. ${ }^{36}$ synthesized poly(dimethylsiloxane)-poly(ethylene glycol) methyl ether acrylate (PDMS-PEGMEA)-based co-polymer membranes via UV initiated one-pot thiol-ene reaction to fabricate elastic polymer materials used for gas separation application. Fang et al. ${ }^{37}$ used thiol-ene reaction to prepare two flexible and colorless phosphorous-sulfide polymer films based on a phosphorus-containing derivative of aromatic aldehyde (4hydroxybenaldehyde). Grewal et al. ${ }^{38}$ and Suk et $a l .{ }^{39}$ reported polymer electrolytes based on a crosslinked network formed via thiol-ene reaction using a thermal initiator. However, it is difficult to obtain an ideal 1:1 stoichiometric reactivity through conventional free radical-mediated addition, which means the simultaneous existence of thiol-ene and ene-ene reaction will most probably pose difficulties for the acquisition of well-defined polymer structure. ${ }^{40}$ To tackle this problem, several approaches are proposed by researchers. Bowman and co-workers ${ }^{41-43}$ synthesized visible-lightsensitive photo-base generators applied in thiol-Michael addition reactions, which 
allows a stoichiometric reaction of both thiol and vinyl functional groups and enables homogeneous network formation. Photopolymerization, as well as the introduction of allyl groups, has been an effective method to develop a controlled network through precise design of the polymer structure, but the complicated synthesis and severe operation condition limit the practical application. Thus, a convenient fabrication process is necessary to form PEs with improved ionic conductivity, high thermal stability, and excellent cycling performance, which can be achieved by using thiolMichael addition. Thiol-Michael addition is modular in nature, highly efficient, and exhibits stoichiometric reactivity of $1: 1$, hence classified as a "click" reaction. By the adjunction of minimal dosage of catalysts (base or nucleophilic reagent) under ambient temperature, it can occur without any exposure to heat or light. In recent years, the thiolMichael addition bas been employed in a large extent of applications, such as small molecule synthesis, surface functionalization, bioconjugation, tissue engineering, dendrimer synthesis, and polymer network synthesis. ${ }^{32}$

The self-catalyzed strategy is an attractive method to fabricate PEs via a simple preparation routine with the lithium salts employed as ion sources on one hand and as catalysts on the other hand. In 2001, Tsutsumi and co-workers ${ }^{44}$ reported that various lithium salts could initiate the cationic ring-opening polymerization (ROP) of bisoxetanes, indicating the potential of self-catalyzed strategy in polymer electrolyte field. Cui et al. ${ }^{45}$ reported a crosslinked PE by a self-catalyzed strategy and in-situ technology via a facile cationic polymerization initiated by lithium salts. Recently, Li et al. ${ }^{46}$ used $\mathrm{LiPF}_{6}$ to induce the cationic polymerization of the ether-based 1,3-dioxolane and 1,2- 
dimethoxyethane liquid electrolyte and fabricated quasi-solid gel PEs. Archer et al. ${ }^{47}$ reported cationic aluminum species-initiated ROP of 1,3-dioxolane inside an electrochemical cell to produce PEs. The self-catalyzed strategy offers incomparable advantages including facile preparation procedure, efficiency, high production and low costs. Yet, the uncontrollability of chain-growth polymerization is hardly satisfactory if the formation of a well-defined polymer electrolyte network is desired. More importantly, compared with electrolytes formed via the self-catalyzed strategy, which are neat polymer matrices, preparing composite polymer electrolytes with inorganic nanofillers introduced is an effective strategy to enhance the ionic conductivity and cycling stability of LIBs. Several studies on organic-inorganic hybrid polymer electrolytes have certificated the mechanism of ionic conductivity enhancement, the interactions between polymer matrix and inorganic fillers at the interface. ${ }^{48}$ First, due to chemical or/and physical interactions, polymer segments can be attracted by the surface sites of ceramic fillers, providing amorphous-rich areas as $\mathrm{Li}^{+}$transport channels near surface region of inorganic fillers. Second, there are intense interaction between anionic groups of lithium salts and chemical groups of ceramic fillers, promoting the lithium salts dissociation and leading to the increase of free $\mathrm{Li}^{+}$ concentration at the interface. Third, the interaction between polymer chains and inorganic fillers could influence the local conformation of segments in polymer, which probably provides $\mathrm{Li}^{+}$-conductive substructures for polymer matrix. Moreover, compared with neat polymer matrix, the cycle stability of composite polymer electrolytes could be improved because the mechanical strength inorganic fillers 
provided is helpful to prevent the growth of lithium dendrites. ${ }^{49}$ Cui et al.${ }^{50}$ reported a composite polymer electrolyte with vertically aligned ceramic-polymer interfaces, achieving high interfacial ionic conductivity and long cycle life when compared to the PE without nanofillers.

Herein, we applied the thiol-Michael addition as a platform to fabricate crosslinked electrolytes with well-defined network by employing a selection of multifunctional thiols, poly(ethylene glycol) diacrylate (PEGDA, $M_{\mathrm{n}}=200,400$, or 600 ) with triethylamine (TEA) as a catalyst in the presence of lithium salts (Figure 1). Studies on the polymerization kinetics denote that lithium salts (lithium perchlorate, lithium bis(trifluoromethanesulfonyl)imide and lithium trifluoromethanesulfonate) are capable of significantly accelerating the base-catalyzed thiol-Michael addition, which enables them to act as ion sources as well as co-catalysts in the polymerization. Moreover, some other alkali metal salts including sodium perchlorate and potassium perchlorate have also shown the same effect as the lithium salts. The novel selfcatalyzed strategy for the base-catalyzed one-pot thiol-Michael addition reaction under ambient temperature described in the present work provides a facile fabricating procedure of PEs. Furthermore, we introduce the thiol-decorated polyhedral oligomeric silsesquioxane (POSS-SH, Figure S1, Supporting Information) into electrolyte networks, which plays an important role in promoting the thermal performance and decreasing the crystallinity of PEs because of the intramolecular organic-inorganic hybrid structure. Moreover, the ideal 1:1 stoichiometric reactivity of thiol group and acrylate group will be conducive to the uniform dispersion of POSS and effectively 
avoid agglomeration of nano-particles, which can lead to negative impact on polymer electrolytes, including growth of lithium dendrite, poor interfacial contact between electrode and polymer electrolytes, and increase of interfacial impedance. As a result of the cross-linked structure and presence of the inorganic component, the ionic conductivity and mechanical property of PEs are also enhanced. The constructed LIBs on the basis of these PEs as separators, lithium iron phosphate (LFP) as cathode and lithium metal as anode show impressive electrochemical performances including a stabilized plating/stripping process and promising cycling property.
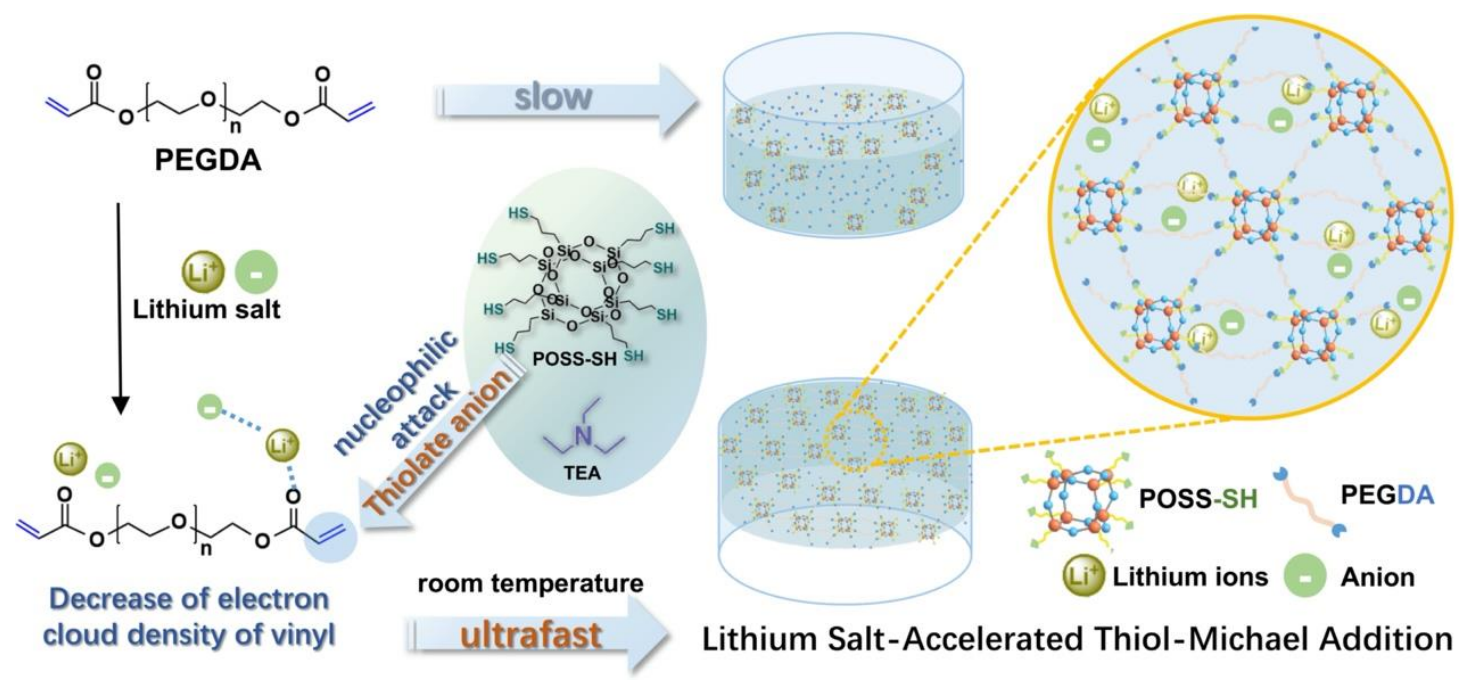

Figure 1. Schematic illustration of the formation of PEs using PEGDA 600 and POSS-SH catalyzed by TEA in the presence of lithium salts.

\section{EXPERIMENTAL SECTION}

Materials. (3-Mercaptopropyl)trimethoxysilane (KH-590, 95\%, Aladdin), trimethylolpropane tris(3-mercaptopropionate) (TMPTMP, 95\%, Sigma-Aldrich), pentaerythritol tetra(3-mercaptopropionate) (PETMP, 90\%, Aladdin), 1-hexanethiol (HT, 96\%, Aladdin), and poly (ethylene glycol) diacrylate (PEGDA, $M_{\mathrm{n}}=200,400$, or 600, Aladdin) were used as received. Triethylamine (TEA) and tetrahydrofuran (THF) 
were dried with calcium hydride and distilled under reduced pressure before use. Lithium $\quad$ perchlorate $\left(\mathrm{LiClO}_{4}, \quad 99.9 \%, \quad\right.$ Aladdin $), \quad$ lithium bis(trifluoromethanesulfonyl)imide $\quad$ (LiTFSI, 99\%, Aladdin), lithium trifluoromethanesulfonate $\left(\mathrm{LiCF}_{3} \mathrm{SO}_{3}, 98 \%\right.$, Aladdin), sodium perchlorate $\left(\mathrm{NaClO}_{4}\right.$, 99.5\%, Aladdin), and potassium perchlorate $\left(\mathrm{KClO}_{4}, 99 \%\right.$, Aladdin) were dried under vacuum and stored in argon-filled glovebox before use. Other chemicals, including hydrochloric acid $(\mathrm{HCl})$, methanol, dichloromethane $\left(\mathrm{CH}_{2} \mathrm{Cl}_{2}\right)$, lithium iron phosphate (LiFePO 4, LFP), acetylene black (AB), poly-(vinylidene fluoride) (PVDF), and $\mathrm{N}$ methyl-2-pyrrolidone (NMP) were purchased locally.

Synthesis and Characterization of POSS-SH. $15 \mathrm{~mL} \mathrm{KH-590} \mathrm{and} 30 \mathrm{~mL} \mathrm{HCl}$ were dissolved in $350 \mathrm{~mL}$ methanol. Then the mixture was stirred vigorously under reflux with oil bath at $90{ }^{\circ} \mathrm{C}$ for $24 \mathrm{~h}$. The reaction product was separated by centrifugation to obtain white precipitate and washed with methanol to give the crude product. The crude product was poured into $\mathrm{H}_{2} \mathrm{O}$ and extracted with $\mathrm{CH}_{2} \mathrm{Cl}_{2}$. The organic layers were washed with $\mathrm{H}_{2} \mathrm{O}$ for several times, and then dried with $\mathrm{Na}_{2} \mathrm{SO}_{4}$. Finally, the product was evaporated on a rotary evaporator and dried under vacuum at $60{ }^{\circ} \mathrm{C}$ for $24 \mathrm{~h}$. The ${ }^{1} \mathrm{H}$ NMR spectra of prepared POSS-SH is listed in Figure S1. The characteristic peaks at $0.77,1.71$ and $2.57 \mathrm{ppm}$ represent protons of three different methylene respectively. Meanwhile, the characteristic peak at $1.38 \mathrm{ppm}$ is assigned to the proton of thiol group. And the mass spectroscopy of POSS-SH is shown in Figure S2, which suggests that the polyhedral oligomeric silsesquioxane conform to the $m / z$ of $\mathrm{T}_{8}$ conformation plus $\mathrm{Cl}^{-}$. 
Fabrication of Polymer Electrolytes. PEs were prepared through a solution casting technique and thiol-Michael addition with TEA as the catalyst and $\mathrm{LiClO}_{4}$ as the cocatalyst. PEGDA $\left(M_{\mathrm{n}}=600,2.5 \mathrm{mmol}\right), \mathrm{POSS}-\mathrm{SH}($ thiol $/ \mathrm{vinyl}=1: 1,0.625 \mathrm{mmol})$ and $\mathrm{LiClO}_{4}\left(\mathrm{EO} / \mathrm{Li}^{+}=16: 1,1.68 \mathrm{mmol}\right)$ were dissolved in THF $(10 \mathrm{~mL})$ in a round flask and stirred for $3 \mathrm{~h}$ at room temperature. TEA $(1 \mathrm{wt} \%, 30 \mu \mathrm{L})$ was then dripped into the flask. The solution was stirred vigorously for $10 \mathrm{~s}$ and then cast in a polytetrafluoroethylene (PTFE) mold. The reaction occurred under air atmosphere and at room temperature, and the membranes were dried under vacuum at $60{ }^{\circ} \mathrm{C}$ for $24 \mathrm{~h}$ to remove THF. The PEs were obtained and stored in a glove box.

Characterization of Polymer Electrolytes. NMR spectra was measured with $\mathrm{CDCl}_{3}$ as solvent by a Bruker AV400 NMR spectrometer. FT-IR spectroscopy was performed on an FT interferometer (Equinox 55, Bruker, Germany) over the range of 4000-400 $\mathrm{cm}^{-1}$. The homogeneity of PEs was estimated by scanning electron microscopy (SEM) and energy dispersive X-ray (EDX) mapping (Nova NanoSEM450, FEI, Netherlands).

Thermogravimetric analysis (TGA, 4000 PerkinElmer, USA) under $\mathrm{N}_{2}$ with a heating rate of $10{ }^{\circ} \mathrm{C} \mathrm{min}^{-1}$ from 30 to $800{ }^{\circ} \mathrm{C}$ and different scanning calorimetry (DSC, Q2000, TA, USA) under $\mathrm{N}_{2}$ atmosphere with a ramp rate of $10{ }^{\circ} \mathrm{C} \mathrm{min}^{-1}$ from -90 to 90 ${ }^{\circ} \mathrm{C}$ were employed to characterize the thermal performance of the PEs.

The ionic conductivity of PEs was determined using an electrochemical test system (Autolab PGSTAR302N, Netherlands) via electrochemical impedance (EIS) analysis. The data were collected with temperatures ranging from $30^{\circ} \mathrm{C}$ to $110{ }^{\circ} \mathrm{C}$ at 10 ${ }^{\circ} \mathrm{C}$ intervals over a frequency range from $1 \mathrm{MHz}$ to $100 \mathrm{~Hz}$. The PEs membranes were 
sandwiched between two stainless steel (SS) electrodes. The ionic conductivity was calculated via the equation $\sigma=L /\left(\mathrm{S} R_{\mathrm{b}}\right)$, where $L$ is the thickness of the polymer electrolyte membrane, $\mathrm{S}$ is the contact area between SS electrode and electrolyte, and $R_{\mathrm{b}}$ is the bulk electrolyte resistance.

The electrochemical stability of PEs was estimated via linear sweep voltammograms (LSV) using the Li $\mid$ PEs $\mid$ SS cells at a scan rate of $0.1 \mathrm{mV} \mathrm{s}^{-1}$ over the range of $0-6 \mathrm{~V}$ at $60{ }^{\circ} \mathrm{C}$. The $\mathrm{Li}|\mathrm{PEs}| \mathrm{Li}$ cells were applied to evaluate the lithium ion transference number $\left(t_{\mathrm{Li}+}\right)$ by the equation $t_{\mathrm{Li}}{ }^{+}=I_{\mathrm{S}}\left(\Delta V-I_{0} R_{0}\right) / I_{0}\left(\Delta V-I_{\mathrm{S}} R_{\mathrm{S}}\right)$. The cell was polarized at $10 \mathrm{mV}(\Delta V)$ to determine the currents including the initial $\left(I_{0}\right)$ and the steady state $\left(I_{\mathrm{S}}\right)$ until the current was steady. Interfacial resistances were obtained before $\left(R_{0}\right)$ and after $\left(R_{\mathrm{S}}\right)$ the polarization.

The lithium electrodeposition was employed to investigate the interfacial stability between PEs and lithium metal using Li | Li CR2032 coin cells. The plating/stripping efficiency of Li metal was tested with a current density of $0.05 \mathrm{~mA} \mathrm{~cm}^{-2}$ at $60{ }^{\circ} \mathrm{C}$.

$\mathrm{LiFePO}_{4}$, carbon black, and PVDF were mixed with a weight ratio of $8: 1: 1$. The slurry was coated on aluminum foil and dried under vacuum at $85{ }^{\circ} \mathrm{C}$ for $24 \mathrm{~h}$. The CR2032 coin cells were assembled with PEs, Li anode and LFP cathode in an argonfilled glovebox. The charge-discharge and cycling performances were tested at $60{ }^{\circ} \mathrm{C}$ under the potential window of $2.5-4.2 \mathrm{~V}$ by a battery testing system (LANHE CT2001A).

DFT Calculations. The computational work was carried out using the Gaussian09 suite of programs. ${ }^{51}$ Gas-phase geometry optimizations were performed without any 
symmetry constraint using the B3LYP functional and the 6-31G(d,p) basis functions for all atoms. Dispersion interactions were taken into account by Grimme's D3 empirical method during the geometry optimizations (B3LYP-D3). ${ }^{52}$ All final geometries were characterized as stationary points by verifying that all second derivatives of the energy were positive. Thermochemical corrections were obtained at $298.15 \mathrm{~K}$ on the basis of frequency calculations, using the standard approximations (ideal gas, rigid rotor and harmonic oscillator). A solvation correction was carried out on the gas-phase optimized molecules by fixed-geometry calculations in the presence of a polarizable continuum with the Gaussian09 library values for the permittivity of chloroform $(\varepsilon=4.7113)$ or THF $(\varepsilon=7.4257)$. A further correction of $1.95 \mathrm{kcal} \mathrm{mol}^{-1}$ was applied to bring the $\mathrm{G}$ values from the gas phase $(1 \mathrm{~atm})$ to the solution $\left(1 \mathrm{~mol} \mathrm{~L}^{-1}\right)$ standard state. ${ }^{53}$ The NMR spectra in chloroform solution were calculated by the Gaussian09 package using the standard Gauge-Independent Atomic Orbital (GIAO) method. ${ }^{54}$

\section{RESULT AND DISCUSSION}

Physical Structure and Characterizations. Figure S3 presents typical images of the ultrafast formation of a cross-linking network by PEGDA $_{600}$ and pentaerythritol tetra(3mercaptopropionate) (PETMP) via TEA-catalyzed thiol-Michael addition in the presence of several types of alkali metal salts within 30 seconds at room temperature. Continuous observation of the reaction catalyzed only by TEA shows that no crosslinked network forms after 3 hours. Images of the corresponding reaction of PEGDA600 and POSS-SH are depicted in Figure 2a, where $5 \mathrm{~mL}$ of THF was added in each experiment to guarantee full dissolution of POSS-SH. The reaction is slower than that 
with PETMP, but the gelification was achieved within $10 \mathrm{~min}$ in the presence of $\mathrm{LiClO}_{4}$ and LiTFSI, whereas the solution containing TEA only changed from the liquid to the solid state after $60 \mathrm{~h}$. It is obvious that this self-catalyzed strategy via thiol-Michael addition allows the rapid construction of PEs. The Fourier transform infrared (FT-IR) analysis shows that the characteristic peaks of the POSS-SH thiol groups at $2550 \mathrm{~cm}^{-1}$ and of the PEGDA 600 vinyl moiety at $1630 \mathrm{~cm}^{-1}$ fade away after the thiol-Michael addition (Figure S4), confirming that the PEGDA600 and multifunctional thiols monomers have reacted completely. The uniform distribution of carbon, oxygen, silicon, and sulfur elements, shown by the energy dispersive X-ray (EDX) analysis of crosssection (Figure 2b), suggests that no significant inorganic nanoparticles aggregation occurs (the original SEM image is shown in Figure S5). This good dispersibility of inorganic fillers is beneficial for the improvement of the mechanical properties. ${ }^{55}$

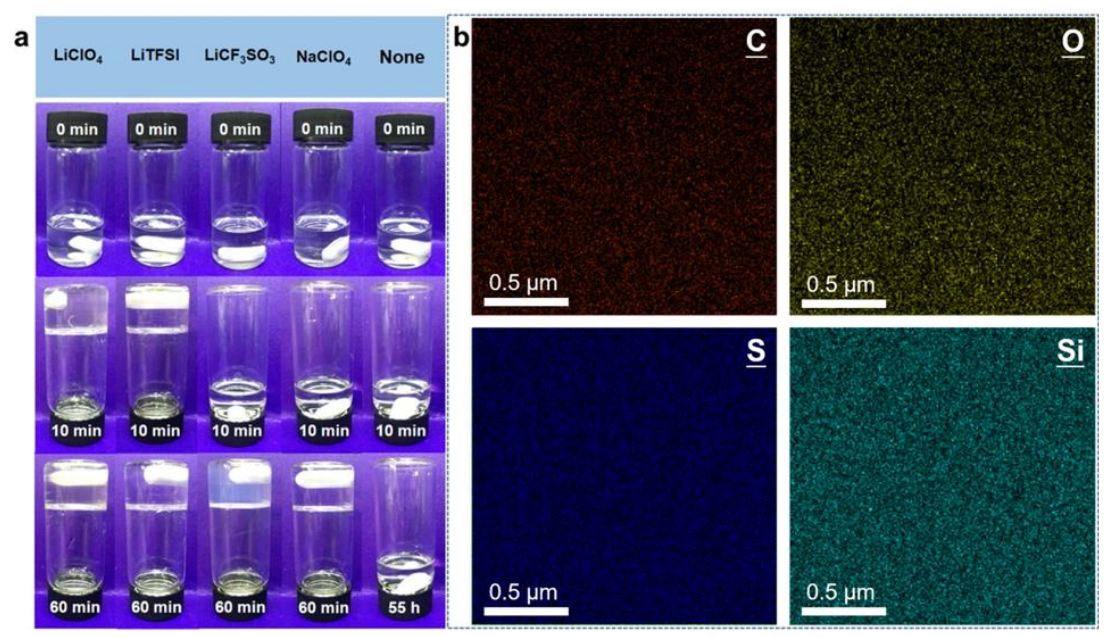

Figure 2. (a) Digital images of PEGDA 600 and POSS-SH mixed with alkali metal salts. (b) EDX maps of PEGDA $600-\mathrm{S}-\mathrm{POSS}$.

The real-time FT-IR spectroscopy was also employed to reveal the reaction kinetics of the TEA-catalyzed thiol-Michael addition using PEGDA 200 and 1hexanethiol (HT) as model substrates by monitoring the disappearance of acrylate and 
thiol peaks (Figure S6). In the absence of $\mathrm{LiClO}_{4}$, this addition reaction proceeded slowly, reaching only about $3 \%$ conversion of both vinyl and thiol groups in $30 \mathrm{~min}$, whereas the reaction proceeds to nearly full conversion in $30 \mathrm{~min}$ in the presence of the salt (Figures 3a and 3b). The kinetics of the reaction does not strongly depend on the $\mathrm{PEGDA}_{200}: \mathrm{LiClO}_{4}$ ratio (Figure S7). Figure S8 shows that no significant conversion of the thiol and vinyl groups for the mixture of PEGDA 200 and HT takes place after $1 \mathrm{~h}$ in the absence of TEA, even if $\mathrm{LiClO}_{4}$ is present $\left(\mathrm{PEGDA}_{200}: \mathrm{LiClO}_{4}=20: 1\right)$. This result clearly establishes that both TEA and $\mathrm{LiClO}_{4}$ are essential to accelerate the reaction. The time-conversion curves for the reactions carried out in the presence of a few other alkali metal salts, including LiTFSI, $\mathrm{LiCF}_{3} \mathrm{SO}_{3}, \mathrm{NaClO}_{4}$, and $\mathrm{KClO}_{4}($ Figures 3a and 3b) illustrate that they also function as co-catalysts, especially LiTFSI, $\mathrm{LiCF}_{3} \mathrm{SO}_{3}$ and $\mathrm{NaClO}_{4}$.

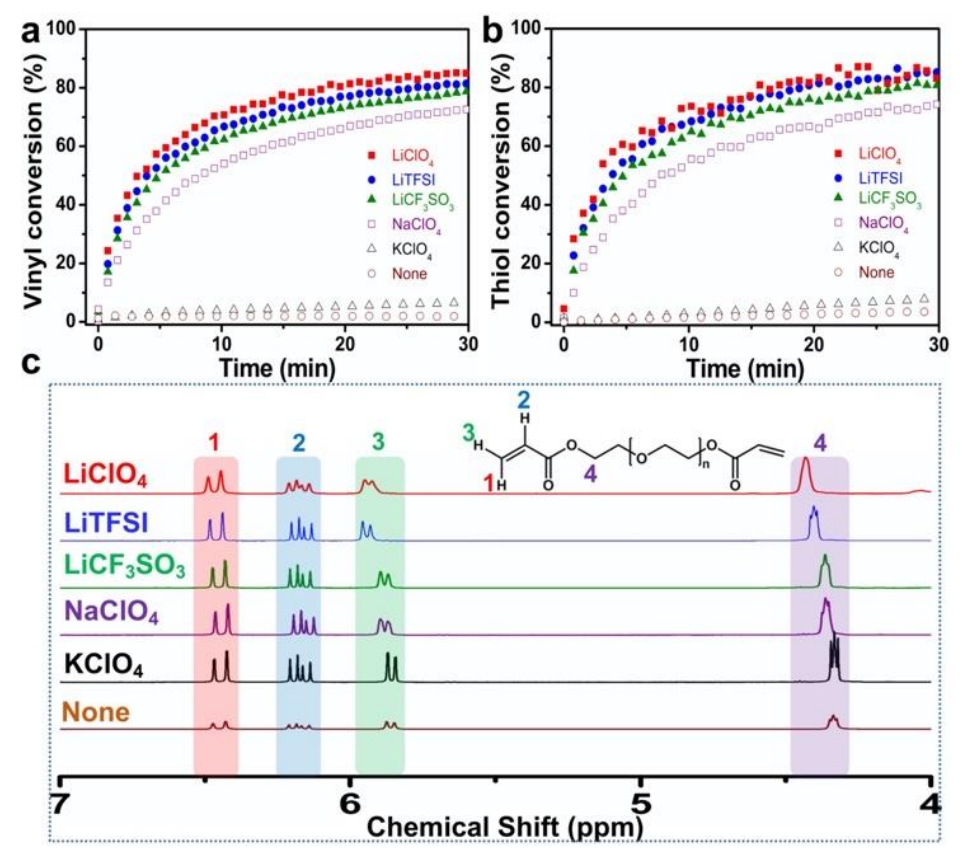

Figure 3. Conversion against time of vinyl (a) and thiol (b) group for the TEA-catalyzed thiolMichael addition of PEGDA $_{200}$ and 1-hexanethiol (HT). [HT] : [PEGDA 200$]:[T E A]=2: 1: 0.043$ (thiol : vinyl $=1: 1)$ in the presence of different alkali metal salts $\left(\left[\mathrm{PEGDA}_{200}\right]:\right.$ [salts] $\left.=20: 1\right)$. (c) ${ }^{1} \mathrm{H}$ NMR spectra $\left(\mathrm{CDCl}_{3}\right)$ of $\mathrm{PEGDA}_{600}$ with different alkali metal salts $\left(\left[\mathrm{PEGDA}_{600}\right]\right.$ : [salts] = 1:2). 
DFT Calculations and Mechanistic Aspects. It is known that the double bond conjugation in acrylate substrates renders the vinyl group electron deficient and therefore suitable for the thiol-Michael addition because the nucleophilic attack by a thiolate anion is accelerated. In addition, stronger electron withdrawing groups should lead to greater electron deficiency and therefore to higher reactivity. We can imagine that coordination of $\mathrm{Li}^{+}$to the oxygen from carbonyl moiety of the acrylate group decreases the vinyl group electron density, thus leading to a faster reaction. To evaluate this hypothesis, we tested the interaction between different salts and the acrylate group by ${ }^{1} \mathrm{H}$ NMR spectroscopy in $\mathrm{CDCl}_{3}$ (Figure 3c), where all salts were fully dissolved. In comparison with pure PEGDA $_{600}$, the methylene proton signals of the $\mathrm{PEGDA}_{600} / \mathrm{LiClO}_{4}$ mixture shift to lower field, suggesting a decreased electron density for the vinyl group. The resonance shifts are greater for greater $\mathrm{LiClO}_{4}$ to $\mathrm{PEGDA}_{600}$ ratios (Figure S9a). The resonance shift is also evident for the other lithium salts, particularly for LiTFSI where the larger anion may favor a stronger salt dissociation, and also for $\mathrm{NaClO}_{4}$, whereas $\mathrm{KClO}_{4}$ has a negligible effect. The position of methylene proton signals also remains essentially unchanged when PEGDA $_{600}$ is mixed with TEA only (Figure S9c), indicating that TEA does not have the same effect of decreasing the vinyl electron density.

The above hypotheses were also supported by density-functional theory (DFT) calculations, which provided, in addition, an insight into the reaction mechanism. The effect of the salt interaction with the acrylate function was probed by performing calculations on adducts of methyl acrylate, as a model substrate, with $\mathrm{MtClO}_{4}(\mathrm{Mt}=\mathrm{Li}$, 
$\mathrm{Na}, \mathrm{K}$ ) in the presence of a polarizable continuum to model the chloroform solvent. Full details are provided in the Supporting Information. Since chloroform has poor coordinating properties, the salt was introduced in the calculation without explicit solvent molecules. In addition to showing a favorable interaction in the order $\mathrm{Li}>\mathrm{Na}>$ $\mathrm{K}\left(\Delta \mathrm{G}_{\mathrm{D} 3,298 \mathrm{~K}, \mathrm{CHCl} 3}=-19.1,-15.7\right.$ and $-10.8 \mathrm{kcal} \mathrm{mol}^{-1}$, respectively $)$, the calculations predict that the $\mathrm{O} \cdots \mathrm{Mt}$ interaction lengthens the $\mathrm{O}=\mathrm{C}$ bond and slightly shortens the (O) $\mathrm{C}-\mathrm{C}$ bond, whereas the vinyl $\mathrm{C}=\mathrm{C}$ bond remains practically unaltered, while increasing the Mulliken charge on all three vinyl $\mathrm{H}$ atoms (details in Table S1). These effects are again decreasing in the order $\mathrm{Li}>\mathrm{Na}>\mathrm{K}$. Finally, the calculations predict a downfield shift of the ${ }^{1} \mathrm{H}$ NMR resonance for all three vinyl $\mathrm{H}$ atoms, relative to free MA, in agreement with the experimental trend (Table S1).

The DFT calculations cannot pinpoint the role of the cation on the activation barrier for the thiol-Michael addition, because the effects of the explicit coordination of solvent molecules (THF) to the alkali cation and of ion pairing cannot be easily modelled computationally. The calculations have provided, however, useful information on the reaction mechanism, which allow the suggestion of the possible role of the cation. The reaction pathway was probed using again MA as a model substrate and $\mathrm{MeSH}$ as a computational model for the thiol reagent. A polarizable continuum model with the permittivity of THF, which was the reaction solvent, was used in this case. Michael additions are known to proceed by nucleophilic attack at the $C_{\beta}$ and yield an enolate intermediate, followed by quenching by protonation, see Scheme S1a. In the absence of base, the nucleophile (MeSH) is too weak and cannot yield the enolate 
intermediate. Rather, the assistance by a second MeSH molecule is necessary and the reaction proceeds by a concerted mechanism, with the simultaneous delivery of the thiolate from one $\mathrm{MeSH}$ molecule to $\mathrm{C}_{\beta}$ and the proton from the second $\mathrm{MeSH}$ molecule to $\mathrm{C}_{\alpha}$, with a high barrier $\left(\Delta G_{298, \mathrm{THF}, \mathrm{MM}}=36.1 \mathrm{kcal} \mathrm{mol}^{-1}\right)$. The mechanism is presented in Scheme S1b and the energy profile is shown in Figure S10.

The energy barrier for the thiol addition is greatly reduced upon thiol deprotonation. The putative free enolate $\mathrm{MeSCH}_{2} \mathrm{CH}=\mathrm{C}(\mathrm{OMe}) \mathrm{O}^{-}$product resulting from addition of the thiolate anion $\left(\mathrm{MeS}^{-}\right)$could not be obtained as a local energy minimum, converging instead to a loose $\mathrm{MA}^{\cdots} \mathrm{SMe}^{-}$adduct with a $\mathrm{S} \cdots \mathrm{C}_{\beta}$ contact of $2.888 \AA$, which is much longer than in the final $\mathrm{MeS}-\mathrm{CH}_{2} \mathrm{CH}_{2} \mathrm{COOMe}$ product $(1.834$ $\AA$ ). This adduct is destabilized relative to the sum of the reagents by $3.0 \mathrm{kcal} \mathrm{mol}^{-1}$. Addition of the proton-delivering thiol molecule to the system further raises the free energy, although only slightly $\left(3.2 \mathrm{kcal} \mathrm{mol}^{-1}\right)$ and produces a van der Waals adduct between MA and the homoconjugate thiol-thiolate pair, [MeSH$\left.{ }^{\cdots}{ }^{\mathrm{SMe}}\right]^{-}$, without any MeSH $\cdots$ MA interaction. The nucleophilic attack is very facile, with a free energy barrier of only $6.9 \mathrm{kcal} \mathrm{mol}^{-1}$ relative to the sum of all reagents, to yield an intermediate, $\left[\mathrm{MeSCH}_{2} \mathrm{CH}(\mathrm{COOMe})\right]^{-\cdots} \mathrm{HSMe}$, which is located at essentially the same free energy as the transition state. In this intermediate, a significant negative charge is localized on the $\mathrm{C}_{\alpha}$ atom, which is slightly pyramidalized, and the proton delivering MeSH molecule establishes a $\mathrm{C}_{\alpha} \cdots \mathrm{H}-\mathrm{SMe}$ interaction. Then, proton transfer to this intermediate is essentially barrierless, as shown by a relaxed scan (the transition state could not be located). Hence, the anionic addition pathway indeed occurs in a stepwise manner, but 
the intermediate is better described as a carbanion than as an enolate, see Scheme S1c. However, we must keep into account that the generation of the thiolate anion is thermodynamically unfavorable, because the conjugate acid of $\mathrm{NEt}_{3}$, namely the ammonium cation $\mathrm{Et}_{3} \mathrm{NH}^{+}$, is a stronger acid than the thiol. Indeed, a ${ }^{1} \mathrm{H}$ investigation of the reaction between 1-hexanethiol and $\mathrm{NEt}_{3}$ gave no evidence of proton transfer (Figure S11). The DFT calculations indicate that $\mathrm{NEt}_{3}$ and the model thiol $\mathrm{MeSH}$ produce an $\mathrm{H}$-bonded MeS-H$\cdots \mathrm{NEt}_{3}$ adduct, located $0.4 \mathrm{kcal} \mathrm{mol}^{-1}$ higher in free energy, and the subsequent proton transfer is highly endoergic $\left(\Delta G_{298, \mathrm{THF}, 1 \mathrm{M}}=25.3 \mathrm{kcal}\right.$ $\mathrm{mol}^{-1}$ for the sum of the separated ions, $\mathrm{NHEt}_{3}{ }^{+}$and $\mathrm{MeS}^{-}$). The $\mathrm{NHEt}_{3}{ }^{+} \ldots-\mathrm{SMe}$ ion pair did not yield a stable minimum, reverting back to the H-bonded adduct during the optimization. Hence, the overall barrier for the $\mathrm{NEt}_{3}$-catalyzed thiol Michael addition to acrylate is only slightly decreased (to $32.2 \mathrm{kcal} \mathrm{mol}^{-1}$, see Figure S10) when also considering the cost of the thiol deprotonation.

The experimental results clearly demonstrate that the presence of an alkali metal cation reduces the reaction energy span. However, the computational quantification of this effect is not straightforward because, as stated above, solvent coordination and ion pairing/free ion equilibria are not trivial to model. Optimization attempts of the intermediate enolate, $\mathrm{MeS}-\mathrm{CH}_{2} \mathrm{CH}=\mathrm{C}(\mathrm{OMe})\left(\mathrm{O}^{-}{ }^{+} \mathrm{Cat}\right)$ converged in all cases to the sum of the reagents $(\mathrm{MA} \cdots \mathrm{Cat}(\mathrm{SMe}))$, whether a naked metal ion $\left(\mathrm{Mt}^{+}\right)$or a more realistic model of the solvated cation $\left(\left[\mathrm{Mt}\left(\mathrm{Me}_{2} \mathrm{O}\right)_{3}\right]^{+}\right.$, with the $\mathrm{Me}_{2} \mathrm{O}$ ligands used as the computational model for THF), was used as cation. A stable local minimum could only be obtained for the anti-conformation of the $\mathrm{C}_{\alpha}-\mathrm{C}_{\beta}$ bond, separating the MeS group 
from the cation. The $\mathrm{MeSCH}_{2} \mathrm{CH}=\mathrm{C}(\mathrm{OMe})\left[\mathrm{OMt}\left(\mathrm{Me}_{2} \mathrm{O}\right)_{3}\right]$ enolates were weakly destabilized relative to the sum of the $\mathrm{MA}$ and $\mathrm{MeS}\left[\mathrm{Mt}\left(\mathrm{Me}_{2} \mathrm{O}\right)_{3}\right]$ reagents by about the same amount for the three cations ( $\left.\mathrm{Li}, 2.0 ; \mathrm{Na}, 1.7 ; \mathrm{K}, 2.1 \mathrm{kcal} \mathrm{mol}^{-1}\right)$. Local minima could be located, however, after adding a MeSH molecule to the systems with the naked cations, which also corresponds to the addition of $\mathrm{Mt}^{+}$to the intermediate of the anionic pathway presented above. The optimized geometries of all these intermediates are comparatively shown in Figure $\mathbf{S 1 2}$. All of them show a relatively strong $\mathrm{Mt}^{+} \cdots \mathrm{O}$ interaction, but also feature $\mathrm{Mt}^{+} \cdots \mathrm{S}$ interactions involving both the free $\mathrm{MeSH}$ molecules and the MeS group that is already incorporated in the enolate intermediate. In addition, the $\mathrm{Na}$ and $\mathrm{K}$ systems also show an additional $\mathrm{S}-\mathrm{H} \cdots \mathrm{C}_{\alpha}$ hydrogen bond, like in the cation-free intermediate.

The reaction pathway for the thiolate Michael addition in the presence of $\mathrm{Mt}^{+}$ could also be investigated starting from $\mathrm{MA}, \mathrm{Mt}^{+}\left(\mathrm{SMe}^{-}\right)$and $\mathrm{MeSH}$ and the results are shown in Figures S13-S15. In these cases, the transition states for the final proton transfer step from MeSH to the $\mathrm{C}_{\alpha}$ atom could be optimized, whereas those of the first step ( $\mathrm{MeS}^{-}$addition to the $\mathrm{C}_{\beta}$ atom) could not. All these reactions have relatively low barriers, at about the same energy relative to the sum of the three separate fragments. The initial addition of $\mathrm{Mt}^{+}\left(\mathrm{SMe}^{-}\right)$to $\mathrm{MA}$ is exoergic in the order $\mathrm{Li}>\mathrm{Na}>\mathrm{K}$. Placing these pathways on the same scale relative to $\mathrm{MA}$ (plus $\mathrm{MeSH}, \mathrm{NEt}_{3}$ and $\mathrm{Mt}^{+} \mathrm{ClO}_{4}^{-}$) requires however assessment of the ion metathesis between $\mathrm{Mt}^{+} \mathrm{ClO}_{4}^{-}$and $\mathrm{Et}_{3} \mathrm{NH}^{+} \mathrm{MeS}^{-}$. This was probed using again the naked cation, yielding the results shown in Figures S13-S15. The most interesting result is that the ion metathesis is quite favorable, thus 
the proton transfer from MeSH to $\mathrm{NEt}_{3}$ in the presence of $\mathrm{Mt}^{+} \mathrm{ClO}_{4}^{-}$(leading to $\mathrm{MtSMe}$ $+\mathrm{Et}_{3} \mathrm{NH}^{+} \mathrm{ClO}_{4}^{-}$) is less energetically costly than in the absence of salt. These results should not be considered as quantitatively reliable, because of the unrealistic model with neglect of solvent coordination to the alkali cation. Another drastic approximation is the neglect of the ion pair dissociation to the free ions. This dissociation likely becomes more favorable for the larger cations $(\mathrm{K}>\mathrm{Na}>\mathrm{Li})$, thus the energetic cost of the initial proton transfer, which also reflects onto the energy of the rate-determining transition state, is probably greater than what is shown in Figures S13-S15, approaching the energetic cost calculated in the absence of salt in Figure S10. In spite of all these approximations, the study qualitatively suggests that the reaction is accelerated, because the energy needed to bring together the anionic nucleophile and the substrate is lowered, which is owing to the more favorable ion pairing in the $\mathrm{Et}_{3} \mathrm{NH}^{+} \mathrm{ClO}_{4}^{-}$and $\mathrm{Mt}^{+} \mathrm{SMe}^{-}$salts than in the metathesized pair $\left(\mathrm{Mt}^{+} \mathrm{ClO}_{4}^{-}\right.$and $\mathrm{Et}_{3} \mathrm{NH}^{+} \mathrm{SMe}^{-}$.

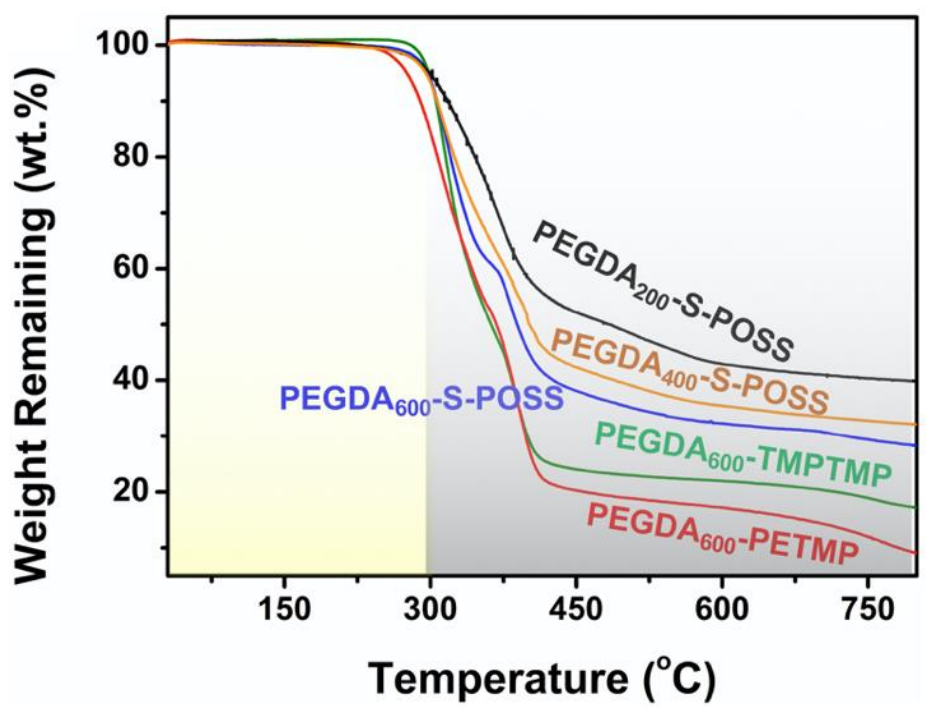

Figure 4. Thermogravimetric analysis (TGA) curves of PEs. 


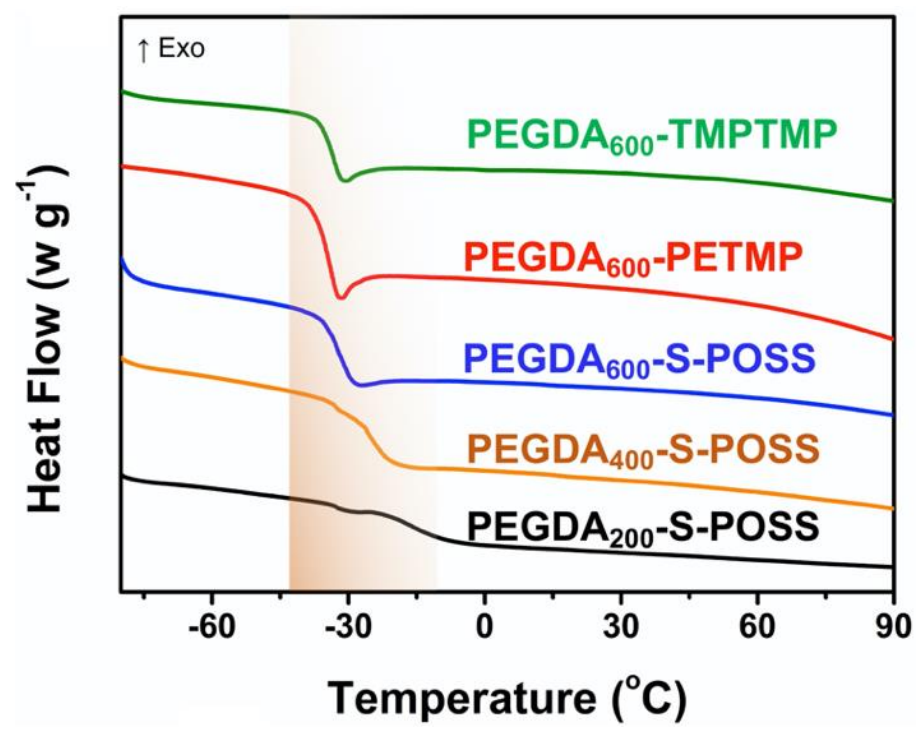

Figure 5. Different scanning calorimetry (DSC) analysis of PEs.

Thermal and Mechanical Properties. Thermal stability is one of the most critical criteria to assess the potential application of PEs in LIBs. As shown in Figure 4, the PEs with the cross-linking structure possess a high decomposition temperature $(\sim 300$ ${ }^{\circ} \mathrm{C}$ ), which is advantageous to the safety performance of LIBs. The glass transition temperature $\left(T_{\mathrm{g}}\right)$ is also a crucial performance standard to evaluate the ionic conductivity of the PEs. In particular, owing to the cation-oxygen complexation in the PEO/Li-salt mixture, the transient physical cross-linking between different PEO segments leads to slower chain relaxation, higher $T_{\mathrm{g}}$, which is to the disadvantage of improvement of ionic conductivity. ${ }^{56} T_{\mathrm{g}}$ decreases with an increase of the PEGDA molecular weight, as shown by the different scanning calorimetry (DSC) analyses (Figure 5 and Table S3), because longer PEGDA chains are capable of promoting the molecular relaxation of the PEs. Besides, the $T_{\mathrm{g}}$ values of PEGDA600-TMPTMP (TMPTMP refers to trimethylolpropane tris(3-mercaptopropionate)) and PEGDA $600^{-}$ PETMP are also lower. The toughness of PEs is important to restrain growth of lithium 
dendrite and prevent from penetration, which can be characterized by tensile test. In general, tensile stress is utilized to assess intrinsic resistance for fracture of polymer materials. ${ }^{57}$ Thus, the tensile stress is available to estimate the resistance for fracture when lithium dendrites penetrate the PEs. ${ }^{58}$ The tensile stress of the PEGDA $600-\mathrm{S}-\mathrm{POSS}$ $\mathrm{PE}$ reaches $310 \mathrm{kPa}$ (Figure S16), demonstrating good mechanical strength and suggesting that this PE can meet the requirements for their practical applications in LIBs.
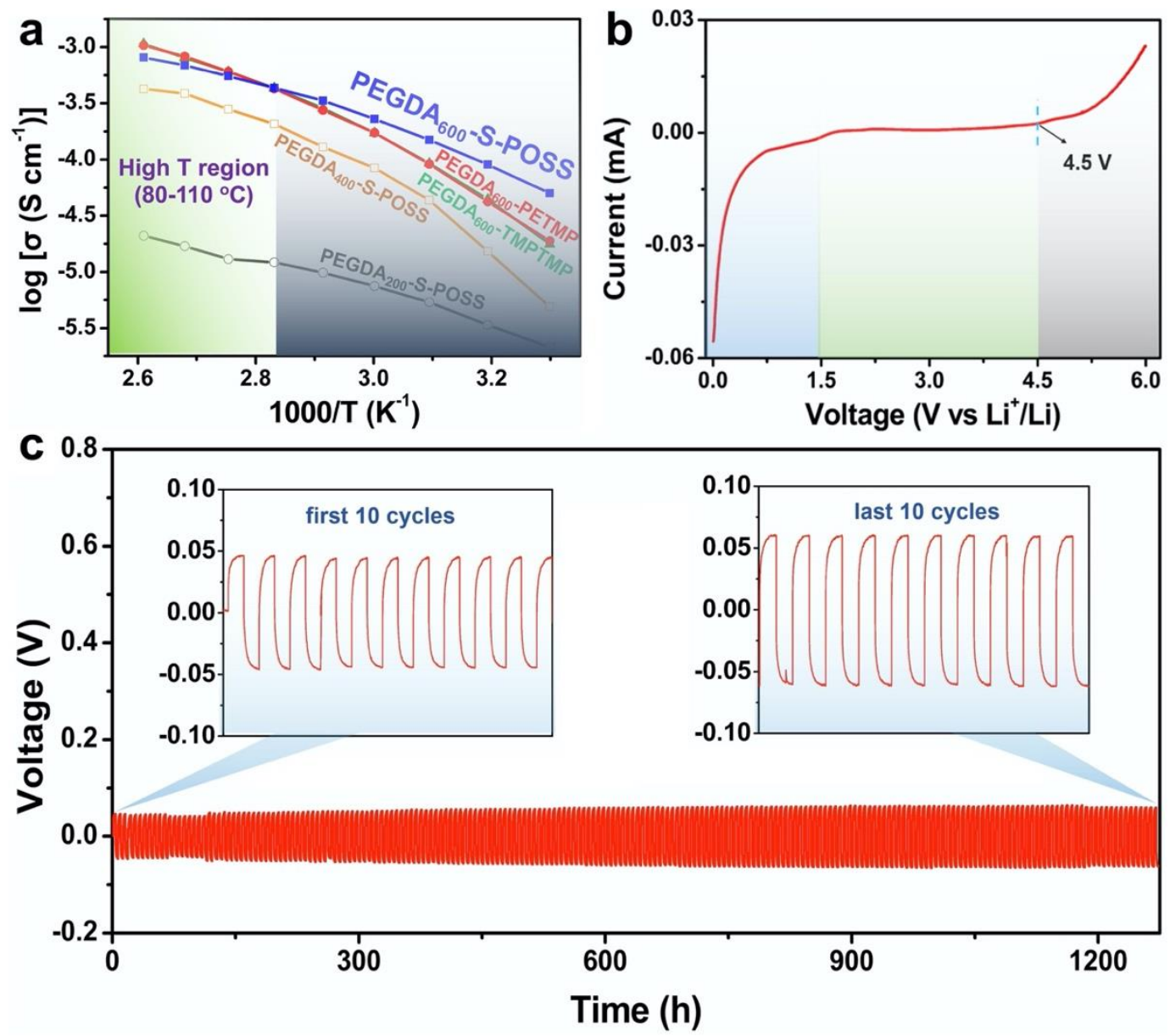

Figure 6. (a) Temperature dependence of the ionic conductivity of PEs. (b) LSV curve of PEGDA $_{600}$-S-POSS at $60^{\circ} \mathrm{C}$. (c) Galvanostatic cycling performance of Li | PEGDA $600-S-P O S S$ | Li symmetric battery measured at $60^{\circ} \mathrm{C}$ with current density of $0.05 \mathrm{~mA} \mathrm{~cm}{ }^{-2}$ with capacity of 0.15 $\mathrm{mAh} \mathrm{cm} \mathrm{c}^{-2}$. Insets: enlarged profiles of the first 10 cycles and last 10 cycles. 
Electrochemical Performances. Generally, only the amorphous fraction of PEO is beneficial to ionic conduction because cation transport is coupled with the PEO mobility. ${ }^{59}$ The ionic conductivity was investigated by electrochemical impedance spectroscopy (EIS), which is a particularly important parameter to estimate the electrochemical performance of PEs. Figure 6a and Figure S17 show that the ionic conductivity increases with an increase of PEGDA chain length. The ionic conductivity of the PEGDA $600-\mathrm{S}-\mathrm{POSS}$ with a longer PEG crosslinking chain and the controlled networks formed via the thiol-Michael reaction is $5.0 \times 10^{-5} \mathrm{~S} \mathrm{~cm}^{-1}$ at $30{ }^{\circ} \mathrm{C}$ and $2.3 \times$ $10^{-4} \mathrm{~S} \mathrm{~cm}^{-1}$ at $60^{\circ} \mathrm{C}$, which is far higher than that of PEGDA200-S-POSS. This is because the PEO chain segment motion depends on the ability to undergo conformational changes. The PEGDA $200-\mathrm{S}-\mathrm{POSS}$ with the short PEG chain possesses the rigid crosslinked network, which is not beneficial to conducting the lithium ions effectively. The ionic conductivity results are in accordance with the $T_{\mathrm{g}}$ change shown in DSC curves, which further indicates that the controlled and flexible cross-linked PEG chain contribute to the ion conduction. Besides the polymer chain length, the inclusion of inorganic components in the polymer electrolytes is also an important avenue to influence ionic conductivity. The observed high ionic conductivity and good mechanical strength in the PEGDA600-S-POSS could be attributed to the uniform hybrid network structure. For PEs based on PEGDA $600, \mathrm{PEGDA}_{600}-\mathrm{S}-\mathrm{POSS}$ is the one giving the highest ionic conductivity below $80{ }^{\circ} \mathrm{C}$. At high temperatures $\left(>80^{\circ} \mathrm{C}\right)$, all PEs arrive the similar conductivity, implying that polymer chains in the PEs have similar dynamics. 
The linear sweep voltammetry (LSV) curve of PEGDA $600-\mathrm{S}-\mathrm{POSS}$, which is sandwiched between Li metal and SS, shows a stabilized current density up to $4.5 \mathrm{~V}$ (Figure 6b), indicating that the PEGDA $_{600}-\mathrm{S}-\mathrm{POSS}$ PE exhibits a major anodic decomposition potential at $4.5 \mathrm{~V}$ vs $\mathrm{Li}^{+} / \mathrm{Li}$. This performance suggests a possible application of the PEGDA $600-\mathrm{S}-\mathrm{POSS}$ in the working charge-discharge potential window between $2.5-4.2 \mathrm{~V}$ because there is no significant decomposition reaction in this voltage range, which is able to satisfy the demand of extensively used $\mathrm{LiFePO}_{4}$ cathode in lithium ion batteries. In addition, the LSV shows an extremely slight and broad reduction profile in the $0.7-1.4 \mathrm{~V}$ range, revealing that a solid electrolyte interface (SEI) layer is formed. From the chart of the AC impedance and DC polarization (Figure S18), the $\mathrm{Li}^{+}$transference number $\left(t_{\mathrm{Li}^{+}}\right)$of PEGDA600-S-POSS at $60{ }^{\circ} \mathrm{C}$ can be calculated as 0.25 . In order to explore the lithium electrodeposition in PEs, Li I

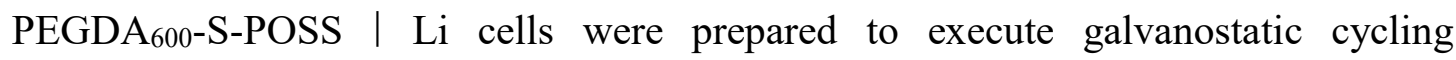
experiments at $60{ }^{\circ} \mathrm{C}$. To evaluate the long-term cycling stability of the LIBs based on the polymer electrolytes fabricated via lithium salt-induced thiol-Michael reaction, the symmetric Li | PEGDA600-S-POSS | Li cells were prepared to execute galvanostatic cycling experiments at $60{ }^{\circ} \mathrm{C}$. To simulate the lithium stripping/plating process, we designed a cycling procedure of three-hours for both charge and discharge with a current density of $0.05 \mathrm{~mA} \mathrm{~cm}^{-2}$ (Figure 6c). The voltage-time curve is flat and stable, no decrease in the voltage and no short circuit were observed with a constant polarization for up to $1270 \mathrm{~h}$, demonstrating the good compatibility between the PE and the lithium metal surface. Besides, the impedance evolution is used to evaluate the 
interfacial stability of the polymer electrolytes. Figure S19 shows the nyquist plot of Li | PEGDA600-S-POSS | Li symmetric cell at $60{ }^{\circ} \mathrm{C}$ with varying storage time. The diameter of distorted semicircle corresponds to the interfacial resistance $\left(R_{\mathrm{i}}\right)$ of PEGDA $_{600}-\mathrm{S}-\mathrm{POSS} \mid$ Li. $R_{\mathrm{i}}$ decreased as the storage time increased, and stabilized after 7 days, suggesting a good interfacial stability between PEGDA $600-S-P O S S$ and Li electrodes. ${ }^{60}$ The stable interface is beneficial to reducing the solid-state interface impedance and improving the embedding/de-embedding efficiency of lithium ions on the electrode, and the cycle stability of LIBs can be thus improved.

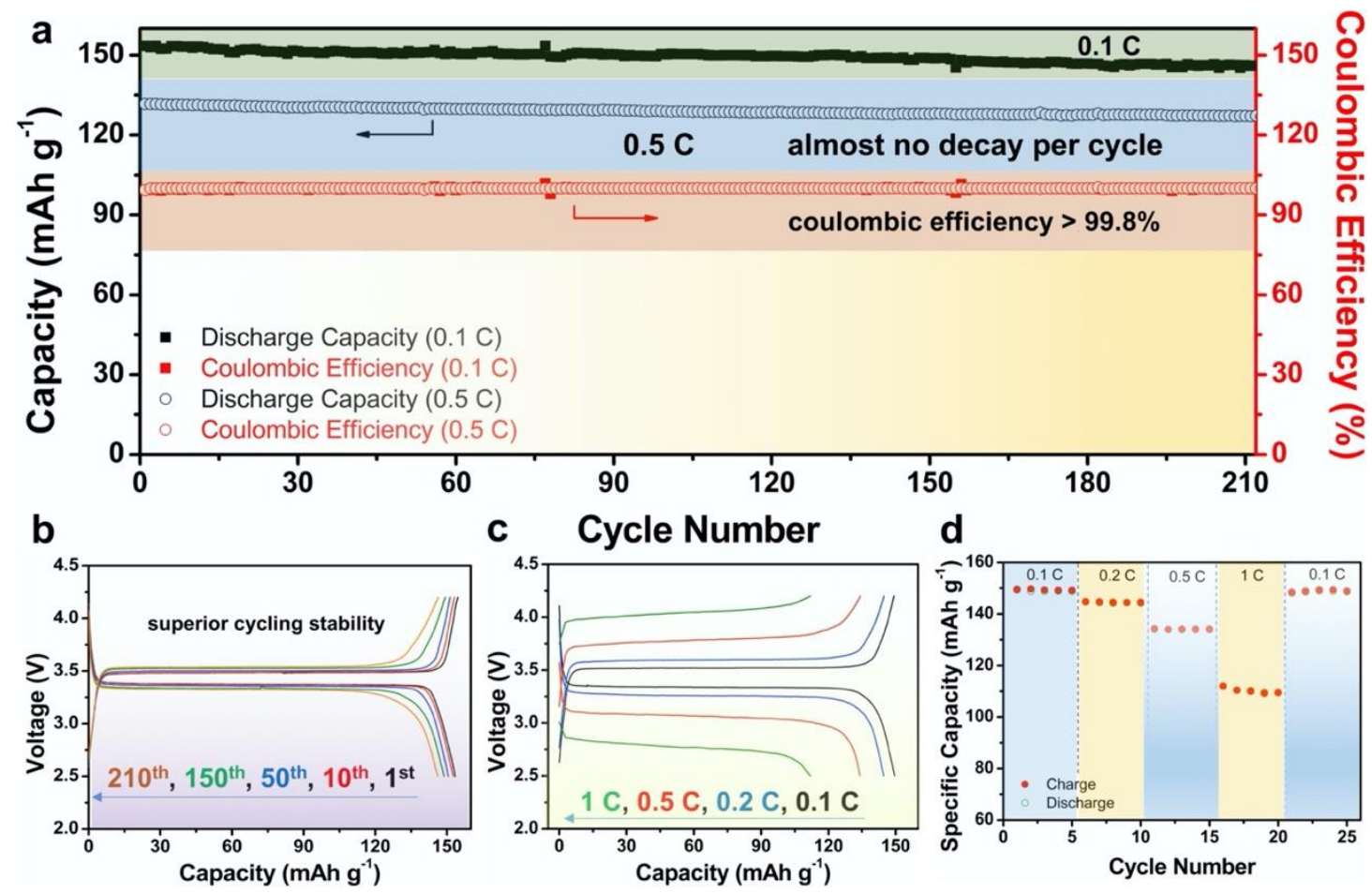

Figure 7. (a) Cycle performance of Li | PEGDA ${ }_{600}$-S-POSS | LFP cell under galvanostatic cycling at $0.1 \mathrm{C}$ and $0.5 \mathrm{C}$ rates. (b) Charge-discharge curves at $0.1 \mathrm{C}$ with PEGDA $600-\mathrm{S}-\mathrm{POSS}$ electrolyte showing low capacity loss and little overpotential. (c) Charge-discharge curves at $0.1 \mathrm{C}\left(15 \mathrm{~mA} \mathrm{~g}^{-1}\right)$, $0.2 \mathrm{C}\left(30 \mathrm{~mA} \mathrm{~g}^{-1}\right), 0.5 \mathrm{C}\left(75 \mathrm{~mA} \mathrm{~g}^{-1}\right)$, and $1 \mathrm{C}\left(150 \mathrm{~mA} \mathrm{~g}^{-1}\right)$, which respectively shows a discharge capacity of $149 \mathrm{mAh} \mathrm{g}^{-1}, 145 \mathrm{~mA} \mathrm{~h} \mathrm{~g}^{-1}, 134 \mathrm{mAh} \mathrm{g}^{-1}$, and $112 \mathrm{mAh} \mathrm{g}^{-1}$. (d) Cycling of Li I PEGDA $_{600-}$ S-POSS I LFP battery at $0.1 \mathrm{C}, 0.2 \mathrm{C}, 0.5 \mathrm{C}$, and $1 \mathrm{C}$. All experiments were conducted at $60{ }^{\circ} \mathrm{C}$. 
To study the potential of the PEGDA $600-\mathrm{S}-\mathrm{POSS}$ PE, LIBs were assembled by combining it with $\mathrm{LiFePO}_{4}$ (LFP) as cathode and lithium metal as anode. Galvanostatic cycling measurements were conducted under $60{ }^{\circ} \mathrm{C}$ at a specific current of $0.1 \mathrm{C}$ to explore the cycle performance of the PE in the 2.5-4.2 V voltage range (Figure 7a). The PE maintained a specific capacity of $146 \mathrm{mAh} \mathrm{g}^{-1}$ and a coulombic efficiency of $99.8 \%$ after 210 cycles. Moreover, the performance of galvanostatic cycling at $0.5 \mathrm{C}$ shows little capacity decay and maintains a high coulombic efficiency (99.9\%) after 200 cycles. The charge-discharge performance under a constant current $(0.1 \mathrm{C})$ at $60{ }^{\circ} \mathrm{C}$ is shown in Figure 7b. The charge and discharge plateaus are observed at $3.49 \mathrm{~V}$ and

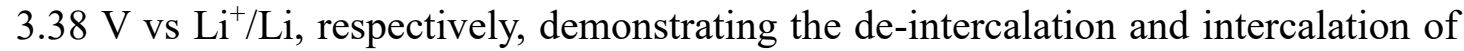
lithium ion. The charge specific capacity is slightly higher than the discharge specific capacity. However, the difference between charge and discharge plateaus decreases as the charging/discharging process keeps going, illustrating that the reversible reaction contributes to the stabilization of the interface. Figure $\mathbf{7 c}$ shows the discharge profiles of Li | PEGDA600-S-POSS | LFP with charge-discharge current densities over the 0.1$1 \mathrm{C}$ range. A discharge capacity of $149 \mathrm{mAh} \mathrm{g}^{-1}$ and a coulombic efficiency of $99.8 \%$ are obtained at $0.1 \mathrm{C}$. As the current density increases, the discharge capacity slightly decreased but was nevertheless maintained at relatively high levels $\left(145 \mathrm{~mA} \mathrm{~h} \mathrm{~g}^{-1}\right.$ at $0.2 \mathrm{C}, 134 \mathrm{mAh} \mathrm{g}^{-1}$ at $0.5 \mathrm{C}$, and $112 \mathrm{mAh} \mathrm{g}^{-1}$ at $\left.1 \mathrm{C}\right)$. The lithium battery was tested at different rates to study the durable rate capacity of the PE. The specific capacity at each current density of the Li | PEGDA600-S-POSS | LFP battery is depicted in Figure 7d. The reversible capacity at $0.2 \mathrm{C}$ is $145 \mathrm{mAh} \mathrm{g}^{-1}$, which is comparably high and nearly 
equal to the capacity of $0.1 \mathrm{C}$. The reversible capacity at $0.5 \mathrm{C}$ and $1 \mathrm{C}$ is $134 \mathrm{mAh} \mathrm{g}^{-1}$ and $112 \mathrm{mAh} \mathrm{g}^{-1}$ respectively, which is approximately $90 \%$ and $75 \%$ of that at $0.1 \mathrm{C}$. More importantly, when the charge-discharge current densities returned to $0.1 \mathrm{C}$, a reversible discharge capacity around $148 \mathrm{mAh} \mathrm{g}^{-1}$ was recovered, demonstrating that the LIBs prepared by using the PEGDA $600-\mathrm{S}-\mathrm{POSS}$ PE have outstanding rate capability.

\section{CONCLUSIONS}

As evidenced above, well-defined cross-linked polymer electrolytes based on PEGDA were successfully prepared by a self-catalyzed strategy using base-catalyzed thiolMichael addition in the presence of lithium (or other alkali metal) salts. In this reaction, the lithium salts act as ion sources and co-catalysts simultaneously. The accelerating action could be correlated with the decrease of electron density in the acrylate vinyl group caused by the interaction between the alkali metal cation and the carbonyl oxygen from acrylate group. This interaction assists the simultaneous delivery of the nucleophilic thiolate anion to the vinyl $\mathrm{C}_{\beta}$ atom and of a proton from a free thiol to the $\mathrm{C}_{\alpha}$ atom. The different equilibria between the ion pair and the free ions for the salts of different alkali metal cations seems responsible for the stronger accelerating factor exhibited for the salts of the smaller Li cation. The PEs exhibited improved ionic conductivity and thermal stability. Moreover, the Li | PEGDA600-S-POSS | LFP cells possessed stable cycling performance. This work paves the way to the development of high-performance polymer batteries via a reliable self-catalyzed strategy. 


\section{ASSOCIATED CONTENT}

\section{Supporting Information}

Scheme S1, Figures S1-S19, and Tables S1-S3

\section{Corresponding Authors}

*E-mail zgxue@mail.hust.edu.cn (Z.X.).

*E-mail rinaldo.poli@lcc-toulouse.fr (R.P.).

\section{ORCID}

Haiyan Peng: 0000-0002-0083-8589

Xiaolin Xie: 0000-0001-5097-7416

Rinaldo Poli: 0000-0002-5220-2515

Zhigang Xue: 0000-0003-2335-9537

\section{Notes}

The authors declare no competing financial interest

\section{ACKNOWLEDGMENT}

We are grateful to the National Natural Science Foundation of China (51973073, and 51703080), Natural Science Foundation of Hubei Scientific Committee (2018CFA059), and Applied and Fundamental Frontier Program of Wuhan (2019010701011409) for support of this work. We are also grateful to the CALMIP mesocenter of the University of Toulouse for the allocation of computational resources, 
and the Analytical and Testing Center of Huazhong University of Science and Technology for use of measurement facilities.

\section{REFERENCES}

(1) Armand, M.; Tarascon, J-M., Building Better Batteries. Nature 2008, 451, 652-657.

(2) Kang, B.; Ceder, G., Battery Materials for Ultrafast Charging and Discharging. Nature 2009, 458, 190-193.

(3) Aricò, A. S.; Bruce, P.; Scrosati, B.; Tarascon, J-M.; Schalkwijk, W. V., Nanostructured Materials for Advanced Energy Conversion and Storage Devices. Nat. Mater. 2005, 4, 366-377.

(4) Winter, M.; Barnett, B.; Xu, K., Before Li Ion Batteries. Chem. Rev. 2018, 118, 11433-11456.

(5) Cao, Y.; Li, M.; Lu, J.; Liu, J.; Amine, K., Bridging the Academic and Industrial Metrics for Next-Generation Practical Batteries. Nat. Nanotechnol. 2019, 14, 200-207.

(6) Goodenough, J. B.; Park, K. S., The Li-Ion Rechargeable Battery: A Perspective. J. Am. Chem. Soc. 2013, 135, 1167-76.

(7) Tarascon, J.-M.; Armand, M., Issues and Challenges Facing Rechargeable Lithium Batteries. Nature 2001, 414, 369-367.

(8) Hammami, A.; Raymond, N.; Armand, M., Lithium-Ion Batteries: Runaway Risk of Forming Toxic Compounds. Nature 2003, 424, 635-636.

(9) Lopez, J.; Mackanic, D. G.; Cui, Y.; Bao, Z., Designing Polymers for Advanced Battery Chemistries. Nat. Rev. Mater. 2019, 4, 312-330.

(10)Zhou, D.; Shanmukaraj, D.; Tkacheva, A.; Armand, M.; Wang, G., Polymer 
Electrolytes for Lithium-Based Batteries: Advances and Prospects. Chem 2019, 5, 2326-2352.

(11) Manthiram, A.; Yu, X. W.; Wang, S. F., Lithium Battery Chemistries Enabled by Solid-State Electrolytes. Nat. Rev. Mater. 2017, 2, 16103.

(12)Miller, T. F.; Wang, Z.-G.; Coates, G. W.; Balsara, N. P., Designing Polymer Electrolytes for Safe and High Capacity Rechargeable Lithium Batteries. Acc. Chem. Res. 2017, 50, 590-593.

(13)Xue, Z.; He, D.; Xie, X., Poly(ethylene oxide)-Based Electrolytes for Lithium-Ion Batteries. J. Mater. Chem. A 2015, 3, 19218-19253.

(14)Xu, H.; Chien, P. H.; Shi, J.; Li, Y.; Wu, N.; Liu, Y.; Hu, Y. Y.; Goodenough, J. B., High-Performance All-Solid-State Batteries Enabled by Salt Bonding to Perovskite in Poly(ethylene oxide). Proc. Natl. Acad. Sci. U S A 2019, 116, 18815-18821.

(15)Croce, F.; Appetecchi, G. B.; Persi, L.; Scrosati, B., Nanocomposite Polymer Electrolytes for Lithium Batteries. Nature 1998, 394, 456-458.

(16)Zeng, X.-X.; Yin, Y.-X.; Li, N.-W.; Du, W.-C.; Guo, Y.-G.; Wan, L.-J., Reshaping Lithium Plating/Stripping Behavior via Bifunctional Polymer Electrolyte for RoomTemperature Solid Li Metal Batteries. J. Am. Chem. Soc. 2016, 138, 15825-15828.

(17) Choudhury, S.; Mangal, R.; Agrawal, A.; Archer, L. A., A Highly Reversible Room-Temperature Lithium Metal Battery Based on Crosslinked Hairy Nanoparticles. Nat. Commun. 2015, 6, 10101.

(18)Choudhury, S.; Stalin, S.; Vu, D.; Warren, A.; Deng, Y.; Biswal, P.; Archer, L. A., Solid-State Polymer Electrolytes for High-Performance Lithium Metal Batteries. Nat. 
Commun. 2019, 10, 4398.

(19)Lu, Q.; He, Y. B.; Yu, Q.; Li, B.; Kaneti, Y. V.; Yao, Y.; Kang, F.; Yang, Q. H., Dendrite-Free, High-Rate, Long-Life Lithium Metal Batteries with A 3D Cross-Linked Network Polymer Electrolyte. Adv. Mater. 2017, 29, 1604460.

(20)Yu, R.; Li, S.; Chen, G.; Zuo, C.; Zhou, B.; Ni, M.; Peng, H.; Xie, X.; Xue, Z., Monochromatic "Photoinitibitor"-Mediated Holographic Photopolymer Electrolytes for Lithium-Ion Batteries. Adv. Sci. 2019, 6, 1900205 (2019).

(21)Zuo, C.; Yang, M.; Wang, Z.; Jiang, K.; Li, S.; Luo, W.; He, D.; Liu, C.; Xie, X.; Xue, Z., Cyclophosphazene-Based Hybrid Polymer Electrolytes Obtained via EpoxyAmine Reaction for High-Performance All-Solid-State Lithium-Ion Batteries. J. Mater. Chem. A 2019, 7, 18871-18879.

(22)Lin, D. C.; Yuen, P. Y.; Liu, Y. Y.; Liu, W.; Liu, N.; Dauskardt, R. H.; Cui, Y., A Silica-Aerogel-Reinforced Composite Polymer Electrolyte with High Ionic Conductivity and High Modulus. Adv. Mater. 2018, 30, 1802661.

(23)Wan, J.; Xie, J.; Kong, X.; Liu, Z.; Liu, K.; Shi, F.; Pei, A.; Chen, H.; Chen, W.; Chen, J.; Zhang, X.; Zong, L.; Wang, J.; Chen, L. Q.; Qin, J.; Cui, Y., Ultrathin, Flexible, Solid Polymer Composite Electrolyte Enabled with Aligned Nanoporous Host for Lithium Batteries. Nat. Nanotechnol. 2019, 14, 705-711.

(24)Gao, Y.; Yan, Z.; Gray, J. L.; He, X.; Wang, D.; Chen, T.; Huang, Q.; Li, Y. C.; Wang, H.; Kim, S. H.; Mallouk, T. E.; Wang, D., Polymer-Inorganic Solid-Electrolyte Interphase for Stable Lithium Metal Batteries under Lean Electrolyte Conditions. Nat. Mater. 2019, 18, 384-389. 
(25)Lin, D.; Liu, W.; Liu, Y.; Lee, H. R.; Hsu, P.-C.; Liu, K.; Cui, Y., High Ionic Conductivity of Composite Solid Polymer Electrolyte via In Situ Synthesis of Monodispersed $\mathrm{SiO}_{2}$ Nanospheres in Poly(ethylene oxide). Nano Lett. 2016, 16, 459465.

(26)Pan, Q.; Smith, D. M.; Qi, H.; Wang, S.; Li, C. Y., Hybrid Electrolytes with Controlled Network Structures for Lithium Metal Batteries. Adv. Mater. 2015, 27, 59956001.

(27)Zhou, B.; Jo, Y. H.; Wang, R.; He, D.; Zhou, X.; Xie, X.; Xue, Z., Self-Healing Composite Polymer Electrolyte Formed via Supramolecular Networks for HighPerformance Lithium-Ion Batteries. J. Mater. Chem. A 2019, 7, 10354-10362.

(28)Hu, J.; Wang, W.; Zhou, B.; Feng, Y.; Xie, X.; Xue, Z., Poly(ethylene oxide)-Based Composite Polymer Electrolytes Embedding with Ionic Bond Modified Nanoparticles for All-Solid-State Lithium-Ion Battery. J. Membr. Sci. 2019, 575, 200-208.

(29)Mather, B. D.; Viswanathan, K.; Miller, K. M.; Long, T. E., Michael Addition Reactions in Macromolecular Design for Emerging Technologies. Prog. Polym. Sci. 2006, 31, 487-531.

(30)Hoyle, C. E.; Lowe, A. B.; Bowman, C. N., Thiol-Click Chemistry: A Multifaceted Toolbox for Small Molecule and Polymer Synthesis. Chem. Soc. Rev. 2010, 39, 13551387.

(31)Nair, D. P.; Podgórski, M.; Chatani, S.; Gong, T.; Xi, W.; Fenoli, C. R.; Bowman, C. N., The Thiol-Michael Addition Click Reaction: A Powerful and Widely Used Tool in Materials Chemistry. Chem. Mater. 2014, 26, 724-744. 
(32)Tasdelen, M. A.; Kiskan, B.; Yagci, Y., Externally Stimulated Click Reactions for Macromolecular Syntheses. Prog. Polym. Sci. 2016, 52, 19-78.

(33)Worrell, B. T.; McBride, M. K.; Lyon, G. B.; Cox, L. M.; Wang, C.; Mavila, S.; Lim, C.-H.; Coley, H. M.; Musgrave, C. B.; Ding, Y.; Bowman, C. N., Bistable and Photoswitchable States of Matter. Nat. Commun. 2018, 9, 2804.

(34)Chatani, S.; Podgórski, M.; Wang, C.; Bowman, C. N., Facile and Efficient Synthesis of Dendrimers and One-Pot Preparation of Dendritic-Linear Polymer Conjugates via a Single Chemistry: Utilization of Kinetically Selective Thiol-Michael Addition Reactions. Macromolecules 2014, 47, 4894-4900.

(35)Hu, J.; Wang, W.; Peng, H.; Guo, M.; Feng, Y.; Xue, Z.; Ye, Y.; Xie, X., Flexible Organic-Inorganic Hybrid Solid Electrolytes Formed via Thiol-Acrylate Photopolymerization. Macromolecules 2017, 50, 1970-1980.

(36) Hong, T.; Cao, P.-F.; Zhao, S.; Li, B.; Smith, C.; Lehmann, M.; Erwin, A. J.; Mahurin, S. M.; Venna, S. R.; Sokolov, A. P.; Saito, T., Tailored $\mathrm{CO}_{2}$-philic Gas Separation Membranes via One-Pot Thiol-ene Chemistry. Macromolecules 2019, 52, 5819-5828.

(37) Fang, L.; Sun, J.; Chen, X.; Tao, Y.; Zhou, J.; Wang, C.; Fang, Q., Phosphorus- and Sulfur-Containing High-Refractive-Index Polymers with High $T_{\mathrm{g}}$ and Transparency Derived from a Bio-Based Aldehyde. Macromolecules 2020, 53, 125-131.

(38)Grewal, M. S.; Tanaka, M.; Kawakami, H., Bifunctional Poly(ethylene glycol) Based Crosslinked Network Polymers as Electrolytes for All-Solid-State Lithium Ion Batteries. Polym. Int. 2019, 68, 684-693. 
(39)Suk, J.; Lee, Y. H.; Kim, D. Y.; Kim, D. W.; Cho, S. Y.; Kim, J. M.; Kang, Y., SemiInterpenetrating Solid Polymer Electrolyte Based on Thiol-Ene Cross-Linker for AllSolid-State Lithium Batteries. J. Power Sources 2016, 334, 154-161.

(40)Zhong, Y.; Nguyen, G. T. M.; Plesse, C.; Vidal, F.; Jager, E. W. H., Tailorable, 3D Structured and Micro-Patternable Ionogels for Flexible and Stretchable Electrochemical Devices. J. Mater. Chem. C 2019, 7, 256-266.

(41)Xi, W.; Peng, H.; Aguirre-Soto, A.; Kloxin, C. J.; Stansbury, J. W.; Bowman, C. N., Spatial and Temporal Control of Thiol-Michael Addition via Photocaged Superbase in Photopatterning and Two-Stage Polymer Networks Formation. Macromolecules 2014, 47, 6159-6165.

(42)Zhang, X.; Xi, W.; Gao, G.; Wang, X.; Stansbury, J. W.; Bowman, C. N., oNitrobenzyl-Based Photobase Generators: Efficient Photoinitiators for Visible-Light Induced Thiol-Michael Addition Photopolymerization. ACS Macro Lett. 2018, 7, 852857.

(43)Huang, S.; Sinha, J.; Podgórski, M.; Zhang, X.; Claudino, M.; Bowman, C. N., Mechanistic Modeling of the Thiol-Michael Addition Polymerization Kinetics: Structural Effects of the Thiol And Vinyl Monomers. Macromolecules 2018, 51, 59795988.

(44)Miwa, Y.; Tsutsumi, H.; Oishi, T., Polymerization of Bis-Oxetanes Consisting of Oligo-Ethylene Oxide Chain with Lithium Salts as Initiators. Polym. J. 2001, 33, 568574.

(45)Cui, Y.; Liang, X.; Chai, J.; Cui, Z.; Wang, Q.; He, W.; Liu, X.; Liu, Z.; Cui, G.; 
Feng, J., High Performance Solid Polymer Electrolytes for Rechargeable Batteries: A Self-Catalyzed Strategy Toward Facile Synthesis. Adv. Sci. 2017, 4, 1700174.

(46)Liu, F.-Q.; Wang, W.-P.; Yin, Y.-X.; Zhang, S.-F.; Shi, J.-L.; Wang, L.; Zhang, X.D.; Zheng, Y.; Zhou, J.-J.; Li, L.; Guo, Y.-G., Upgrading Traditional Liquid Electrolyte via In Situ Gelation for Future Lithium Metal Batteries. Sci. Adv. 2018, 4, eaat5383.

(47)Zhao, Q.; Liu, X.; Stalin, S.; Khan, K.; Archer, L. A., Solid-State Polymer Electrolytes with In-Built Fast Interfacial Transport for Secondary Lithium Batteries. Nat. Energy 2019, 4, 365-373.

(48) Dirican, M.; Yan, C.; Zhu, P.; Zhang, X., Composite Solid Electrolytes for AllSolid-State Lithium Batteries. Mater. Sci. Eng. R: Rep. 2019, 136, 27-46.

(49) Xia, S.; Lopez, J.; Liang, C.; Zhang, Z.; Bao, Z.; Cui, Y.; Liu, W., High-Rate and Large-Capacity Lithium Metal Anode Enabled by Volume Conformal and SelfHealable Composite Polymer Electrolyte. Adv. Sci. 2019, 6, 1802353.

(50) Zhang, X.; Xie, J.; Shi, F.; Lin, D.; Liu, Y.; Liu, W.; Pei, A.; Gong, Y.; Wang, H.; Liu, K.; Xiang, Y.; Cui, Y., Vertically Aligned and Continuous Nanoscale CeramicPolymer Interfaces in Composite Solid Polymer Electrolytes for Enhanced Ionic Conductivity. Nano Lett. 2018, 18, 3829-3838.

(51)Frisch, M. J.; Trucks, G. W.; Schlegel, H. B.; Scuseria, G. E.; Robb, M. A.; Cheeseman, J. R.; Scalmani, G.; Barone, V.; Mennucci, B.; Petersson, G. A.; Nakatsuji, H.; Caricato, M.; Li, X.; Hratchian, H. P.; Izmaylov, A. F.; Bloino, J.; Zheng, G.; Sonnenberg, J. L.; Hada, M.; Ehara, M.; Toyota, K.; Fukuda, R.; Hasegawa, J.; Ishida, M.; Nakajima, T.; Honda, Y.; Kitao, O.; Nakai, H.; Vreven, T.; Montgomery Jr., J. A.; 
Peralta, J. E.; Ogliaro, F.; Bearpark, M.; Heyd, J. J.; Brothers, E.; Kudin, K. N.; Staroverov, V. N.; Kobayashi, R.; Normand, J.; Raghavachari, K.; Rendell, A.; Burant, J. C.; Iyengar, S. S.; Tomasi, J.; Cossi, M.; Rega, N.; Millam, N. J.; Klene, M.; Knox, J. E.; Cross, J. B.; Bakken, V.; Adamo, C.; Jaramillo, J.; Gomperts, R.; Stratmann, R. E.; Yazyev, O.; Austin, A. J.; Cammi, R.; Pomelli, C.; Ochterski, J. W.; Martin, R. L.; Morokuma, K.; Zakrzewski, V. G.; Voth, G. A.; Salvador, P.; Dannenberg, J. J.; Dapprich, S.; Daniels, A. D.; Farkas, Ö.; Foresman, J. B.; Ortiz, J. V.; Cioslowski, J.; Fox, D. J., Gaussian 09, Revision D.01. Gaussian, Inc.: Wallingford CT, 2009.

(52) Grimme, S.; Antony, J.; Ehrlich, S.; Krieg, H., A Consistent and Accurate Ab Initio Parametrization of Density Functional Dispersion Correction (DFT-D) for the 94 Elements H-Pu. J. Chem. Phys. 2010, 132, 154104.

(53) Bryantsev, V. S.; Diallo, M. S.; Goddard III, W. A., Calculation of Solvation Free Energies of Charged Solutes Using Mixed Cluster/Continuum Models J. Phys. Chem. B 2008, 112, 9709-9719.

(54)Wolinski, K.; Hinton, J. F.; Pulay, P., Efficient Implementation of the GaugeIndependent Atomic Orbital Method for NMR Chemical Shift Calculations. J. Am. Chem. Soc. 1990, 112, 8251-8260.

(55) Tan, G.; Wu, F.; Zhan, C.; Wang, J.; Mu, D.; Lu, J.; Amine, K., Solid-State Li-Ion Batteries Using Fast, Stable, Glassy Nanocomposite Electrolytes for Good Safety and Long Cycle-Life. Nano Lett. 2016, 16, 1960-1968.

(56)Duan, H.; Yin, Y.-X.; Zeng, X.-X.; Li, J.-Y.; Shi, J.-L.; Shi, Y.; Wen, R.; Guo, Y.G.; Wan, L.-J., In-Situ Plasticized Polymer Electrolyte with Double-Network for 
Flexible Solid-State Lithium-Metal Batteries. Energy Storage Mater. 2019, 10, 85-91.

(57) Tanaka, Y.; Kuwabara, R.; Na, Y.-H.; Kurokawa, T.; Gong, J.-P.; Osada, Y., Determination of Fracture Energy of High Strength Double Network Hydrogels. J. Phys. Chem. B 2005, 109, 11559-11562.

(58) Wu, H.; Cao, Y.; Su, H.; Wang, C., Tough Gel Electrolyte Using Double Polymer Network Design for the Safe, Stable Cycling of Lithium Metal Anode. Angew. Chem. Int. Ed. 2018, 57, 1361-1365.

(59) Stoeva, Z.; Martin-Litas, I.; Staunton, E.; Andreev, Y. G.; Bruce, P. G., Ionic Conductivity in the Crystalline Polymer Electrolytes $\mathrm{PEO}_{6}: \mathrm{LiXF}_{6}, \mathrm{X}=\mathrm{P}, \mathrm{As}$, Sb. J. Am. Chem. Soc. 2003, 125, 4619-4626.

(60) Wang, S.; Liu, X.; Wang, A.; Wang, Z.; Chen, J.; Zeng, Q.; Jiang, X.; Zhou, H.; Zhang, L., High-Performance All-Solid-State Polymer Electrolyte with Controllable Conductivity Pathway Formed by Self-Assembly of Reactive Discogen and Immobilized via a Facile Photopolymerization for a Lithium-Ion Battery. ACS Appl. Mater. Interfaces 2018, 10, 25273-25284. 